***Reprinted with permission. No further reproduction is authorized without written permission from PNG Publications. This version of the document is not the version of record.

Figures and/or pictures may be missing from this format of the document.***

\title{
Beliefs of Blue-collar Workers: Stage of Readiness for Exercise
}

\author{
Carolyn L. Blue, RN, PhD, CHES; David R. Black, PhD, MPH, CHES, FAAHB \\ Karen Conrad, RN, MPH, PhD; Kimberlee A. Gretebeck, RN, PhD
}

\begin{abstract}
Objective: To address a theoretical debate regarding contributions of self-efficacy and the theory of planned behavior (TPB) in explaining the amount of variance in stage of readiness to exercise among blue-collar workers. Method: A validated questionnaire was used for assessment. Results: LISREL indicated that self-efficacy had the most influence on stage and TPB constructs were subjugated to self-efficacy.

Univariate analyses indicated that self-efficacy and TPB variables are important for intervention. Conclusions: Self-efficacy plays a major role in explaining exercise stage among high-risk blue-collar workers, and self-efficacy and TPB constructs are important to consider in designing interventions.

Key words: theory of planned behavior, self-efficacy, stage of change, exercise

Am J Health Behav 2003;27(4):408-420
\end{abstract}

$\mathrm{B}$ lue-collar workers, in comparison to the general population or whitecollar workers, are the highest risk for chronic illnesses because of greater inactivity. ${ }^{1-7}$ Only a small proportion of blue-collar workers participate in worksite physical fitness programs and even fewer of these eligible workers become longterm exercisers. ${ }^{8}$ One way to increase the physical activity levels of blue-collar workers is to target them through re-

Carolyn L. Blue, Postdoctoral Fellow and Associate Professor, School of Nursing, Purdue University; David R. Black, Professor, Health Promotion; Health Sciences; Foods and Nutrition; Nursing; Department of Health and Kinesiology, Purdue University, West Lafayette, IN. Karen Conrad, Associate Professor, School of Public Health, University of Illinois-Chicago, Chicago, IL. Kimberlee A. Gretebeck, Assistant Professor, School of Nursing, The University of Michigan, Ann Arbor, MI.

Address correspondence to Dr. Blue, Johnson Hall of Nursing, Purdue University, 502 N. University Street, West Lafayette, IN 47907-2069. E-mail: blue@nursing.purdue.edu cruitment efforts and to design appealing worksite interventions. ${ }^{9}$ Tailoring interventions for blue-collar workers based on theoretically sound research should increase the likelihood for program effectiveness.

The theory of planned behavior (TPB) ${ }^{10}$ and the transtheoretical model (TM) of behavior change ${ }^{11}$ have been used as conceptual frameworks in studies of physical activity. Integrated reviews ${ }^{12-15}$ have shown the following: (a) Attitude has consistently predicted intention to engage in physical activity; (b) subjective norm has been inconsistent in predicting intention to engage in physical activity; (c) perceived behavioral control has predicted intention, but has inconsistently predicted physical activity behavior; and (d) the TPB has been shown to explain/predict physical activity intention and behavior. A synopsis of TM studies ${ }^{16-19}$ has shown (a) individuals have been successfully differentiated by constructs from the TM according to stage of readiness to change physical activity behaviors; (b) participants in the precontemplation and con- 
templation stages reported lower levels of physical activity than did those who were in the action and maintenance stages; and (c) a stage-specific intervention can be successful in advancing subjects between stages of change.

Although both models have demonstrated predictive abilities, there may be benefits to using a multitheoretical approach. Courneya and colleagues ${ }^{20,21}$ indicated that the advantage of the TPB is to explain "why" whereas the TM explains "when" people change their physical activity behavior in stages. The path analysis used by Courneya et $\mathrm{al}^{20,21}$ showed that intention to engage in physical activity was significantly correlated with stage of physical activity, and stage was significantly correlated with physical activity. However, the stage-of-readiness-forphysical-activity construct may be confounded in that the measure includes an intention component (precontemplation, contemplation, and preparation) and a behavior component (action and maintenance).

Another variable investigated in studies of physical activity is self-efficacy. ${ }^{22}$ In a review of the influence of self-efficacy on physical activity, McAuley ${ }^{23}$ concluded the following: (a) Self-efficacy is a significant determinant of exercise adherence; (b) changes in self-efficacy result in positive changes in exercise behavior over time; and (c) future studies should focus on when as well as whether or not a relationship exists between self-efficacy and physical activity.

Self-efficacy also has been found to predict exercise stage ${ }^{24-26}$ and to be significantly related to stage in the behaviorchange process. ${ }^{19-27}$ Researchers ${ }^{17,26}$ found that precontemplators and contemplators had the lowest and maintainers had the highest self-efficacy perceptions. In an exploratory analysis, ${ }^{25}$ self-efficacy was the most important predictor of stage of exercise change. Also, it has been reported that self-efficacy increases as people move through the stages of change from precontemplation to maintenance. ${ }^{17}$

In terms of use of both the TPB and selfefficacy constructs, there is a debate ${ }^{28-31}$ as to whether Ajzen's ${ }^{10}$ perceived behavioral control is the same as Bandura's ${ }^{22}$ self-efficacy. Ajzen ${ }^{10}$ indicated that perceived behavior control "refers to the perceived ease or difficulty of performing the behavior and is assumed to reflect past experience as well as anticipated impediments and obstacles." Perusal of other works by Ajzen ${ }^{32,33}$ clarifies that impediments and obstacles are related to control over external factors that increase or reduce the perceived difficulty related to performing a given behavior. Bandura ${ }^{22}$ stated, "Perceived self-efficacy refers to beliefs in one's capabilities to organize and execute the courses of action required to produce given attainments." Bandura $^{22}$ posited that self-efficacy is the effective application of personal means (personal beliefs about one's self) to conduct a behavior to produce outcomes and without means an agent cannot exercise control over outcomes. Bandura further reported that when perceived self-efficacy is included in statistical modeling, (a) perceived behavioral control makes no independent contribution to performance or the response variable, and (b) attitude and perceived behavioral control would be mediating variables in the path between self-efficacy and the response variable. ${ }^{22}$ Thus, self-efficacy hypothetically should directly influence behavior and also indirectly influence behavior by its relationship to the mediating variables.

The purpose of this research was to address an ongoing theoretical debate about the contributions of constructs from different theories in explaining exercise behavior. This purpose was accomplished by selecting a statistical technique that evaluates the uniqueness of the measures to their constructs and addressing structural relationships in order to examine the strengths of the contributions and the relationships of the constructs modeled. A practical purpose of the study was to identify variables that differentiated stages of readiness to exercise.

\section{METHODS \\ Subjects}

Of the census (N=529) of blue-collar workers in building, grounds, and maintenance departments in a university setting, a validated, self-administered questionnaire was distributed to 522 workers, and a representative sample of 468 (88.5\%) of them completed it. The sample size of 468 was sufficiently large based on a power analysis of alpha at .05 yielding 99\% power ${ }^{34}$ and the LISREL output pertaining to critical $N$ size. Participants were primarily men $(75.9 \%)$ who were married (65.6\%) and white (94.5\%). Their 
mean age was 43.2 years old $(\mathrm{SD}=10.9)$. The largest proportion of subjects reported their highest level of education as high school graduate $(41.5 \%)$, followed by some college (19.4\%), trade or technical school graduate $(19.2 \%)$, college graduates (10.3\%), some high school (7.4\%), and < eighth-grade education (2.2\%). The committee on the use of human subjects approved the study and research protocol.

\section{Procedures}

Subject selection. The purpose of the study was explained at one of 3 mandatory departmental meetings. Workers were assured of voluntary participation and confidentiality. Attendees were asked to complete a questionnaire and to deposit the questionnaire in a drop box if they wished to participate.

Elicitation study. Following Azjen and Fishbein's ${ }^{10,35}$ protocol for questionnaire development, responses obtained from a convenience sample of 21 blue-collar employees during a qualitative elicitation study were used to identify behavioral, normative, and control beliefs for this study. Comparable responses and the most frequent form of responses were grouped together into "modal belief sets." 35 Agreement of judgments from a panel of experts $(n=4)$ in physical activity research and TPB provided evidence for content validity and clarity of the modal belief sets. Likert-type scales were developed from the belief responses representing each modal belief set. Likert-type scales corresponding to each modal belief set also were constructed to measure the evaluation of each belief. Using TPB procedures, ${ }^{35}$ behavioral beliefs were weighted by the outcome evaluation, and normative beliefs were weighted by the motivation to comply with the referent. Control belief measures were unweighted.

Questionnaire. Table 1 provides summary information about the questionnaire items. The Table presents variables used to measure each construct, scales of measurement, response adjectives, number of items, minimum and maximum scores, minimum and maximum item-to-total correlations, and Cronbach alphas.

The questionnaire contained 90 items and was divided into the following sections: (a) TPB (58 items), (b) self-efficacy (9 items), (c) stage of readiness (2 items), (d) response bias (10 items), and (e) demo- graphic questions (11 items). Exercise was defined as moderate or vigorous physical activity for 20 minutes each time, at least 3 times a week during free time and that may make the individual's heart beat fast, and make the individual breathe hard and work up a sweat. ${ }^{36}$ The definition was listed at the top of each page of the questionnaire as referent when answering questions. As Table 1 shows, at least 2 measures for each construct were used in the analyses because multiple measures are essential to assess measurement qualities in linear structural equation modeling. ${ }^{37}$ Because salient beliefs (behavioral beliefs, normative beliefs, and control beliefs) underlie a person's attitude, subjective norm, and perceived behavioral control, the behavioral, normative, and control beliefs were used as indirect measures, and the general measures (attitude, subjective norm, and perceived behavioral control) were used as direct measures for each TPB construct. Principal components factor analyses with oblique rotations confirmed that variables for the behavioral, normative, and control beliefs as well as attitude were correctly clustered according to TPB constructs. All factor analyses results complied with standards of acceptable minimum criterion for factor loadings, eigenvalues, communality, and percent variance explained. ${ }^{38}$ Item-to-total correlations also met the recommended minimum criterion of $.30 .^{38}$ All TPB constructs were operationalized and measured using the method of Azjen and Fishbein. ${ }^{10,35}$ The scores were averaged, and some items were reverse scored so higher scores indicated that the respondent possessed more of the attribute.

TPB constructs. The indirect measure of the attitude construct included a variable pertaining to a salient set of behavioral beliefs that performing exercise would lead to an outcome evaluation that would be either "bad" or "good" (eg, "Gives me more energy" or "Would result in sore muscles"). Items consisted of 12 specific behavioral beliefs multiplied by corresponding outcome evaluations for each of the beliefs. The products were summed and averaged for a weighted belief score. ${ }^{35}$ The direct or general measure of attitude consisted of semantic differential scales to assess the evaluative dimension of exercise behavior (eg, exercise is "unpleasant/pleasant”). ${ }^{39}$ 
Table 1

Descriptive Statistics of Theory of Planned Behavior Constructs, Self-Efficacy, and Stages of Readiness

\begin{tabular}{|c|c|c|c|c|c|c|c|}
\hline Construct & Variable & Scale & Anchors & $\begin{array}{l}\# \\
\text { of } \\
\text { Items }\end{array}$ & $\begin{array}{l}\text { Min/ } \\
\text { Max } \\
\text { Scores }\end{array}$ & $\begin{array}{l}\text { Min/Max } \\
\text { Item-to- } \\
\text { Total }\end{array}$ & Cronbach $\alpha$ \\
\hline \multirow[t]{3}{*}{ Attitude } & $\begin{array}{l}\text { Behavioral } \\
\text { beliefs }^{\mathrm{a}}\end{array}$ & $\begin{array}{l}\text { 5-pt. } \\
\text { Likert-type }\end{array}$ & $\begin{array}{l}1=\text { Very unlikely } \\
5=\text { Very likely }\end{array}$ & 12 & $1-25^{c}$ & $.30-.75$ & .78 \\
\hline & $\begin{array}{l}\text { Outcome } \\
\text { evaluataion }\end{array}$ & $\begin{array}{l}\text { 5-pt. } \\
\text { Likert-type }\end{array}$ & $\begin{array}{l}\text { 1=Extremely bad } \\
5=\text { Extremely good }\end{array}$ & 12 & ${ }^{\mathrm{d}}$ & $\longrightarrow^{\mathrm{d}}$ & ${ }^{\mathrm{d}}$ \\
\hline & Attitude ${ }^{\mathrm{b}}$ & $\begin{array}{l}\text { 7-pt. } \\
\text { Semantic } \\
\text { differential }\end{array}$ & $\begin{array}{l}\text { Unpleasant/pleasant } \\
\text { Boring/interesting } \\
\text { Bad/good } \\
\text { Useless/useful } \\
\text { Worthless/valuable } \\
\text { Harmful/helpful }\end{array}$ & 6 & $1-7$ & $.64-.77$ & .90 \\
\hline \multirow[t]{3}{*}{$\begin{array}{l}\text { Subjective } \\
\text { Norm }\end{array}$} & $\begin{array}{l}\text { Normative } \\
\text { beliefs }^{\mathrm{a}}\end{array}$ & $\begin{array}{l}\text { 5-pt. } \\
\text { Likert-type }\end{array}$ & $\begin{array}{l}\text { 1=Definitely should not } \\
5=\text { Definitely should }\end{array}$ & 6 & $1-25^{c}$ & $.60-.74$ & .86 \\
\hline & $\begin{array}{l}\text { Motivation } \\
\text { to comply }\end{array}$ & $\begin{array}{l}\text { 5-pt. } \\
\text { Likert-type }\end{array}$ & $\begin{array}{l}1=\text { Not at all } \\
5=\text { Very much }\end{array}$ & 6 & ${ }^{\mathrm{d}}$ & ${ }^{\mathrm{d}}$ & ${ }^{\mathrm{d}}$ \\
\hline & $\begin{array}{l}\text { Subjective } \\
\text { norm }^{\mathrm{b}}\end{array}$ & $\begin{array}{l}\text { 5-pt. } \\
\text { Likert-type }\end{array}$ & $\begin{array}{l}1=\text { Strongly do not agree } \\
5=\text { Strongly agree }\end{array}$ & 2 & $1-25$ & $\square^{\mathrm{e}}$ & ${ }^{\mathrm{e}}$ \\
\hline \multirow{3}{*}{$\begin{array}{l}\text { Perceived } \\
\text { Behavioral } \\
\text { Control }\end{array}$} & $\begin{array}{l}\text { Control } \\
\text { beliefs }^{\mathrm{a}}\end{array}$ & $\begin{array}{l}\text { 5-pt. } \\
\text { Likert-type }\end{array}$ & $\begin{array}{l}1=\text { Very easy } \\
5=\text { Very difficult }\end{array}$ & 7 & $1-5$ & $.56-.71$ & .86 \\
\hline & $\begin{array}{l}\text { Perceived } \\
\text { control }^{\mathrm{b}}\end{array}$ & $\begin{array}{l}\text { 5-pt. } \\
\text { Likert-type }\end{array}$ & $\begin{array}{l}1=\text { Absolutely no control } \\
5=\text { Complete control }\end{array}$ & $\begin{array}{l}1 \\
1\end{array}$ & $\begin{array}{l}1-5 \\
1-5\end{array}$ & ${\widetilde{{ }^{e}}}^{\mathrm{e}}$ & ${ }^{\mathrm{e}}{ }^{\mathrm{e}}$ \\
\hline & Difficult ${ }^{\mathrm{b}}$ & $\begin{array}{l}\text { 5-pt. } \\
\text { Likert-type }\end{array}$ & $\begin{array}{l}1=\text { Very difficult } \\
5=\text { Very easy }\end{array}$ & 1 & $1-5$ & ${ }^{e}$ & ${ }^{\mathrm{e}}$ \\
\hline \multirow[t]{2}{*}{ Self-Efficacy } & $\begin{array}{l}\text { External } \\
\text { constraints }\end{array}$ & 3-pt. & $\begin{array}{l}1=\text { No } \\
2=\text { Neutral } \\
3=\text { Yes }\end{array}$ & 4 & $1-3$ & $.63-.80$ & .89 \\
\hline & Personal & 3-pt. & $\begin{array}{l}1=\text { No } \\
2=\text { Neutral } \\
3=\text { Yes }\end{array}$ & 5 & $1-3$ & $.62-.69$ & .83 \\
\hline \multirow[t]{3}{*}{ Intention } & Intend & $\begin{array}{l}\text { 5-pt. } \\
\text { Likert-type }\end{array}$ & $\begin{array}{l}\text { 1=Definitely will not } \\
\text { 5=Definitely will }\end{array}$ & 1 & $1-5$ & ${ }^{\mathrm{e}}$ & ${ }^{\mathrm{e}}$ \\
\hline & Try & $\begin{array}{l}\text { 5-pt. } \\
\text { Likert-type }\end{array}$ & $\begin{array}{l}\text { 1=Definitely will not } \\
5=\text { Definitely will }\end{array}$ & 1 & $1-5$ & $\square^{e}$ & $\underbrace{e}$ \\
\hline & Effort & $\begin{array}{l}\text { 5-pt. } \\
\text { Likert-type }\end{array}$ & $\begin{array}{l}\text { 1=Definitely will not } \\
5=\text { Definitely will }\end{array}$ & 1 & $1-5$ & $\square^{e}$ & ${ }^{\mathrm{e}}$ \\
\hline $\begin{array}{l}\text { Stages of } \\
\text { Readiness }\end{array}$ & Stage & $\begin{array}{l}5 \text {-pt. } \\
\text { Ordinal }\end{array}$ & $\begin{array}{l}\text { Precontemplation: } \\
\text { 1=Do not exercise \& won't } \\
\text { start in next } 2 \text { months. } \\
\text { Contemplation: } \\
\text { 2=Do not exercise, but am thinking } \\
\text { of starting in the next } 2 \text { months. } \\
\text { Preparation: } \\
\text { 3=Currently exercise, but not regularly } \\
\text { Action: }\end{array}$ & 1 & $1-5$ & (continued & n next page) \\
\hline
\end{tabular}




\section{Table 1 (cont'd)}

Descriptive Statistics of Theory of Planned Behavior Constructs, Self-Efficacy, and Stages of Readiness

\begin{tabular}{|c|c|c|c|c|c|c|c|}
\hline Construct & Variable & Scale & Anchors & $\begin{array}{l}\# \\
\text { of } \\
\text { Items }\end{array}$ & $\begin{array}{l}\text { Min/ } \\
\text { Max } \\
\text { Scores }\end{array}$ & $\begin{array}{l}\text { Min/Max } \\
\text { Item-to- } \\
\text { Total }\end{array}$ & Cronbach $\alpha$ \\
\hline & & & $\begin{array}{l}\text { 4=Currently exercise regularly, } \\
\text { but have only begun within the } \\
\text { last } 6 \text { months. } \\
\text { Maintenance: } \\
5=\text { Exercise regularly and have } \\
\text { done so longer than } 6 \text { months. }\end{array}$ & & & & \\
\hline & $\begin{array}{l}\text { Recent } \\
\text { activity }\end{array}$ & $\begin{array}{l}\text { 5-pt. } \\
\text { Likert-type }\end{array}$ & $\begin{array}{l}1=\text { Not at all } \\
5=3 \text { or more times/wk. }\end{array}$ & 1 & $1-5$ & $\longrightarrow^{\mathrm{e}}$ & $\square^{\mathrm{e}}$ \\
\hline \multirow[t]{2}{*}{ Behavior } & $\begin{array}{l}\text { Leisure } \\
\text { activity }^{\mathrm{f}}\end{array}$ & Frequency & $\begin{array}{l}\text { Mild, moderate, and strenuous } \\
\text { activity }\end{array}$ & 3 & $\begin{array}{l}\text { Con- } \\
\text { tinuous }\end{array}$ & $\square^{\mathrm{e}}$ & \\
\hline & $\begin{array}{l}\text { Frequency of } \\
\text { Exercise }^{f, g}\end{array}$ & $\begin{array}{l}\text { 3-pt. } \\
\text { Likert-type }\end{array}$ & $\begin{array}{l}1=\text { Never/rarely } \\
3=\text { Often }\end{array}$ & 1 & $1-3$ & $\square^{\mathrm{e}}$ & $\longrightarrow^{\mathrm{e}}$ \\
\hline
\end{tabular}

a Indirect measures of the constructs.

b Direct measures of constructs.

c Product scores were summed and averaged.

d A part of the product scores used to compute the multivariate statistic.

e ${ }^{\mathrm{e}}=$ Insufficient number of items to compute a multivariate statistics.

f Item from Godin's Leisure Activity Questionnaire.

g Activity enough to workup a "sweat."

The indirect measure of the subjective norm construct was the normative beliefs or the approval or disapproval of "important referents" (eg, "Physician or nurse" or "Spouse or housemate") with respect to exercise and the respondent's motivation to comply with the desires of the referents. The normative belief measures were multiplied by their corresponding motivation to comply and the products summed. The direct measure of subjective norm consisted of 2 items to determine the following: (a) whether most people important to the person thought he/she should or should not exercise and (b) whether or not the respondent wanted to do what most important others thought with respect to exercising. In keeping with the measurement tradition of Ajzen and Fishbein in which they recommend multiplying the normative belief measures with their corresponding motivation to comply, ${ }^{35}$ subjective norm was multiplied by motivation to comply.

The indirect measure of perceived behavioral control was the control beliefs about whether a particular facilitating or inhibiting condition would make exercising easy or difficult (eg, "Having time scheduled for exercise"). The direct measures of perceived behavioral control were (a) how much control the respondent had over performing the behavior and (b) how easy or difficult it would be to perform the behavior.

Self-efficacy. Self-efficacy was measured by the Self-Efficacy for Exercise Scale developed by Sallis et $\mathrm{al}^{40}$ and adapted for use with blue-collar workers by Muto et al. ${ }^{41}$ Factor analysis revealed 2 factors: external constraints (eg, "Exercise when facilities or equipment is poor") and personal constraints (eg, "Set aside time for exercise when you are busy"). Each factor was used as a measure of self-efficacy.

Intention. Intention to exercise was measured with 3 variables. Respondents were asked whether they would intend, try, or make an effort to exercise.

Stage of readiness. Stage of readiness to exercise was measured by a staging scale $^{26}$ and recent 2-month past behavior 
(see Table 1 for the 5 specific stage items). The addition of the second behavioral measure satisfied the measurement requirements for structural equation modeling, ${ }^{42}$ and past behavior is postulated to predict future behavior. ${ }^{10}$ Therefore, both recent and past behavior would be cogent measures of the stage construct.

Exercise behavior. Two variables of exercise were taken from the Godin Leisure Activity Questionnaire. ${ }^{43}$ The first measure required respondents to indicate the times per week they engaged in mild, moderate, or strenuous activity, each of which lasted 15 minutes or more over a typical 7 -day period. These 3 items were weighted by the multiples of metabolic (METs) units of above resting metabolism: strenuous $=9$, moderate $=5$, and mild $=3$ METs. Psychometrically, the sum of the products for the 3 scores was divided by 10 to reduce the value to a comparable unit to other measures of variables included in the covariance matrix for LISREL. ${ }^{44}$ The second measure required respondents to indicate how often they engaged in regular activity long enough to perspire. The following testretest reliabilities have been reported for the strenuous, moderate, light, and total dimensions of the METs and index of perspiration: $.94, .46, .48, .74$, and .80 , respectively. ${ }^{43}$ Concurrent validity has been established with the measure's association with physical fitness criteria. ${ }^{45}$

Response bias. The short version of the Marlow-Crowne Social Desirability Index ${ }^{46}$ was used to assess whether subjects answered in a socially desirable way. Strahan and Gerbasi ${ }^{46}$ reported reliability from .59 to .70 in 4 samples of college students and staff. Correlations between the original 33-item MarlowCrowne Social Desirability Index and the two 10-item scales were all in the $.90 \mathrm{~s}$. The 8 items in the present study that showed the highest Spearman-Brown split-half reliability $(\mathrm{r}=.70)$ were retained for the analyses.

Research design and data analyses. This study used a cross-sectional, survey research design. SPSS/PC ${ }^{47}$ was used to conduct a factor analysis and Cronbach alpha reliability on scales, develop a covariance matrix for the linear structural relations (LISREL) analysis, and compute one-way analyses of variance (ANOVAs) assuming independence of the TPB and self-efficacy variables followed by post hoc
Tukey Honestly Significant Difference Tests. Tukey tests were used to compare adjacent stages only and not all possible comparisons.

The structuralmodel proposed that physical activity behavior was influenced by intention via stage of readiness. Intention was influenced by attitude, perceived behavioral control, and subjective norm. Attitude and perceived behavioral control were influenced by self-efficacy. Selfefficacy and subjective norm constructs were allowed to correlate with each other. The model assumed uncorrelated error terms.

A measurement (confirmatory factor) model was estimated to determine the relationships between the unobserved model constructs (ie, latent variables) and the measured variables (ie, indicators). A structural (path) model was used to specify the underlying relations among the constructs. Overall fit of the model to the data was assessed with root mean square residual; standardized root mean square residual; chi-squared $\left(\chi^{2}\right)$; goodness-of fit index; adjusted goodness-of fit index; and parsimony goodness-of-fit index. The larger (less significant) the probability associated with the $\chi^{2}$, the better the fit of the model to the data. Critical $\mathrm{N}$ values are reported as an indication of power and the minimum sample size required to compute a valid result.

\section{RESULTS \\ Analyses}

Initial. Respondents had a modest social desirability response set in that the mean score on the Social Desirability Scale was $11.16(\mathrm{SD}=1.36)$, nearer the median of the scale that was from 8 to 16 . Pearson correlation coefficients for the social desirability variable and the measures for attitude, subjective norm, perceived behavioral control, self-efficacy, intention, stage, and behavior were all near zero and nonsignificant $(\mathrm{r}=-.001$ to .04). Therefore, social desirability bias does not seem to have a notable influence in this study.

Analyses were conducted to describe the sample, test underlying statistical model assumptions and assess effects of missing data. None of the following regarding model fit suggested a violation of model assumptions and the use of inappropriate statistical models. A very small percentage $(4.9 \%)$ of the cases had miss- 


\begin{tabular}{|llcc|}
\hline & \multicolumn{2}{c|}{ Table 2 } \\
& Measures of Central & Tendency & \\
\hline Construct & Variable & M & S D \\
\hline Attitude & Behavioral beliefs & 13.15 & 3.04 \\
& Attitude & 5.04 & 1.03 \\
Subjective Norm & Normative beliefs & 12.57 & 4.31 \\
& Subjectivenorm & 11.30 & 6.66 \\
Perceived Control & Control beliefs & 3.76 & 0.75 \\
& Control & 3.43 & 1.25 \\
Self-Efficacy & Difficult & 3.03 & 1.27 \\
& External constraints & 1.78 & 0.64 \\
Intention & Personal constraints & 2.16 & 0.67 \\
& Intend & 2.71 & 1.30 \\
Stage of Readiness & Try & 2.94 & 1.32 \\
& Effort & 3.03 & 1.36 \\
Behavior & Stage & 2.77 & 1.29 \\
& Recent activity & 2.44 & 1.51 \\
& Leisure activity & 3.02 & 3.27 \\
& Frequency of exercise & 1.97 & 0.71 \\
\hline
\end{tabular}

ing data. Graphic displays of missing data showed random patterns. Comparison of analyses with and without these cases showed no difference in analyses results. Means were substituted only for the missing response variable values and not for demographic values.

Main. Table 2 provides measures of central tendency for each of the study variables. The mean scores, together with the minimum/maximum scores in Table 1 for the measures of attitude, subjective norm, perceived behavioral control, and self-efficacy, indicate moderate certainty that (a) exercising regularly would lead to positive outcomes and/or that those outcomes would be "good"; (b) respondents were influenced by important others; (c) they perceived behavioral control over carrying out exercise behavior; (d) there were constraints to engaging in exercise behavior; and (e) they intended to engage in exercise behaviors. The mean scores of 2.77 and 2.44 , respectively for stage of readiness and recent activity were low. The mean for behavior indicates that respondents did not exercise.

The following results are not shown in Table 2. As expected, workers who reported they were in the precontemplation (26.1\%) or contemplation (24.4\%) stages did not exercise at all. Another 34.6\% reported they exercised some, but not regularly. Very few workers reported exercising regularly as indicated by the fact that only $6.8 \%$ and $8.1 \%$ were classified in the action and maintenance stages, respectively.

LISREL measurement model. A confirmatory factor analysis of the measures showed the following variables shared their origin with another construct: control beliefs with attitude, and the intention, stage, and behavior constructs. Consequently, the control-belief measure and the intention and behavior constructs were eliminated from the structural equation model. Table 3 shows the squared multiple correlation coefficients [reliability $\left.\left(\mathrm{R}^{2}\right)\right]$ for the measures and lambda coefficients [validity $(\chi)$ ] for the measurement model used in the structural analysis. Values pertaining to $\mathrm{R}^{2}$ were moderate; however, when more than one indicator is used, model structure is normally minimally affected. ${ }^{44}$ The coefficients showed the measures were significantly unique to their construct as shown by the $t$ statistic values in parentheses.

LISREL structural model. Table 4 presents goodness-of-fit results for the initial and best-fitted structural models. Not shown in Table 4 is that the initial structural model included the exogenous variables of self-efficacy and subjective norm and the endogenous variables of attitude, perceived behavior control, and 


\begin{tabular}{|c|c|c|c|c|c|c|}
\hline \multicolumn{7}{|c|}{$\begin{array}{c}\text { Table } 3 \\
\text { Reliability }\left(R^{2}\right) \text { and Standardized Lambda }(\lambda) \text { Estimates } \\
\text { of the Measurement Model }\end{array}$} \\
\hline \multirow[b]{2}{*}{$\begin{array}{l}\text { Measured } \\
\text { Variables }\end{array}$} & & \multicolumn{5}{|c|}{ Constructs } \\
\hline & $\mathbf{R}^{2}$ & $\begin{array}{c}\text { Self- } \\
\text { Efficacy }\end{array}$ & $\begin{array}{l}\text { Subjective } \\
\text { Norm }\end{array}$ & Attitude & $\begin{array}{c}\text { Perceived } \\
\text { Behavioral } \\
\text { Control }\end{array}$ & $\begin{array}{l}\text { Stage of } \\
\text { Readiness }\end{array}$ \\
\hline External Constraints ${ }^{a}$ & .49 & .70 & & & & \\
\hline Personal Constraints & .47 & $\begin{array}{c}.68 \\
(12.45)^{*}\end{array}$ & & & & \\
\hline Normative Beliefs ${ }^{\mathrm{a}}$ & .51 & & .72 & & & \\
\hline Subjective Norm & .37 & & $\begin{array}{c}.61 \\
(8.12)^{*}\end{array}$ & & & \\
\hline Behavioral Beliefs ${ }^{a}$ & .55 & & & .74 & & \\
\hline Attitude & .50 & & & $\begin{array}{c}.71 \\
(13.35)^{*}\end{array}$ & & \\
\hline Difficult $^{a}$ & .74 & & & & .86 & \\
\hline Control & .40 & & & & $\begin{array}{c}.64 \\
(9.74)^{*}\end{array}$ & \\
\hline Stage $^{a}$ & .75 & & & & & .87 \\
\hline Recent Activity & .67 & & & & & $\begin{array}{c}.82 \\
(15.65)^{*}\end{array}$ \\
\hline $\begin{array}{lc}\text { a } & \text { Unstandardized p } \\
* & \text { Values in parenth } \\
& \text { significant } \leq .05 .\end{array}$ & $\begin{array}{l}\text { rame } \\
\text { ses ar }\end{array}$ & $\begin{array}{l}\text { value fixed } \\
\text { t statistics. }\end{array}$ & $\begin{array}{l}\text { to } 1.0 \text {. } \\
\text { The correspon }\end{array}$ & ling minimu & ritical value $f$ & $t \geq 1.96$ and \\
\hline
\end{tabular}

stage of readiness for exercise. In addition to the direct paths from attitude, perceived behavioral control, and subjective norm to stage of readiness, there were proposed paths from self-efficacy to attitude and perceived behavioral control. Consequently in this model, selfefficacy influenced stage of readiness indirectly via its influence on attitude and perceived behavior control.

The $\chi^{2}$ fit statistic for the initial model in Table 4 was significant, indicating that the model implied by the covariance matrix and the observed data fit poorly. The root mean square residual and standardized root mean square residual were modest in that the values only approximate an ideal of 0 . The following values below indicate that the model had a reasonably good fit: (a) standardized root mean square residual near 0; (b) the goodness-of-fit index of .97, which assesses relative amount of variance and covariance accounted for by the model independent of sample size; and (c) the adjusted goodness-of-fit index of .93, which is adjusted for degrees of freedom. ${ }^{42}$ All values in (a) to (c) approximate the ideal of either 0 or 1.0, depending on the fit index. The parsimony goodness-of-fit index was .51, indicating a modestly simplified or "thrifty" model. Based on the modification suggestions in the LISREL output and theoretical considerations, a direct path was added from self-efficacy to stage and because of the negligible negative contribution of subjective norm, it was eliminated. The final model had the best fit and was most parsimonious (see right column of Table 4).

Table 5 shows a further comparison between the initial and the best-fitted model. With respect to the initial model, self-efficacy had a large influence on both 


\section{Table 4 \\ Comparative Goodness of Fit Among the Initial and Best-Fitted Models}

\begin{tabular}{lcc}
\hline Goodness of Fit Measures & Initial Model & ${\text { Best-Fitted } \text { Model }^{\mathbf{b}}}$ \\
\hline Likelihood Test $\left(\boldsymbol{\chi}^{2}\right)\left(\mathbf{L}^{2}\right)$ & 81.73 & 15.03 \\
df & 29 & 15 \\
$\mathbf{P}$ & $<.0000006$ & .450 \\
Root Mean Square Residual & .301 & .049 \\
Standardized Root Mean Square Residual & .040 & .017 \\
Goodness-of-fit Index & .965 & .992 \\
Adjusted Goodness-of-fit Index & .934 & .981 \\
Parsimony Goodness-of-fit Index & .509 & .413 \\
Increment in LR & & 66.70 \\
df & 1 & 1 \\
$\mathbf{P}$ & & $<.005$ \\
\hline a Represents the likelihood ratio for asymptotic & $\boldsymbol{\chi}^{2}$ distribution calculated as the difference in $\boldsymbol{\chi}^{2}$ \\
& between the initial and best-fitting models. \\
b Subjective norm was eliminated and a direct path was added from self-efficacy to stage.
\end{tabular}

attitude and perceived control. Attitude had a larger direct effect on stage than did perceived behavioral control. Unexpectedly, subjective norm had a small, but significant, negative effect on stage. Although not shown in the Table, the variance explained in attitude and perceived behavioral control by self-efficacy was $88 \%$ and $37 \%$, respectively, and the variance explained in stage of readiness by attitude, perceived behavioral control, and subjective norm was 54\%.

The lower half of Table 5 shows direct, indirect, and total effects for the bestfitted model. Self-efficacy continued to have a large direct effect on attitude and perceived behavioral control. The direct effect of self-efficacy on stage also was large and significant. However, the direct effect of attitude on stage diminished and became nonsignificant. Perceived behavioral control had a smaller, but significant, direct effect on stage. Therefore, the indirect effect of self-efficacy on stage became small and nonsignificant with the addition of a direct path from selfefficacy to stage. The variance in attitude and perceived behavioral control explained by self-efficacy was $67 \%$ and $40 \%$, respectively, and the variance explained in stage by attitude, perceived behavioral control, and self-efficacy was $68 \%$. This best-fitted model is depicted in
Figure 1.

Analyses of variances (ANOVAs). Oneway ANOVAs between stages of readiness (independent variable) and the variables from the TPB and self-efficacy (dependent variables) showed significant differences. The omnibus results for behavioral beliefs, normative beliefs, control beliefs, attitude, subjective norm, difficulty exercising, control of exercise, and external and personal constraints (self-efficacy) were all significant, $F(4,463)=23.16,12.63$, $11.93,27.72,6.50,29.68,8.96,27.00$, 29.38, $\mathrm{P}<.0001$, respectively.

The Tukey Honestly Significant Difference (HSD) post hoc multiple comparisons test indicated statistically significant mean differences between the stage "do not intend to start exercise" (precontemplation) and "thinking about starting exercise" (contemplation) for behavioral beliefs, normative beliefs, control beliefs, attitude, subjective norm, and external and personal constraints (ie, selfefficacy measures), Tukey HSD $(4,463)=-$ $1.69,-2.72,-.48,-.61,-3.91,-.23,-.34$, $\mathrm{P} \geq .027$, respectively. Between "thinking about starting exercise" (contemplation) and "exercising but not regularly" (preparation), the only 2 mean differences that were significant were external and personal constraints, Tukey HSD $(4,463)=$ $.23,-.21, \mathrm{P} \geq .029$, respectively. Between 
Table 5

Decomposition of Effects for the Initial and Best-Fitted Models

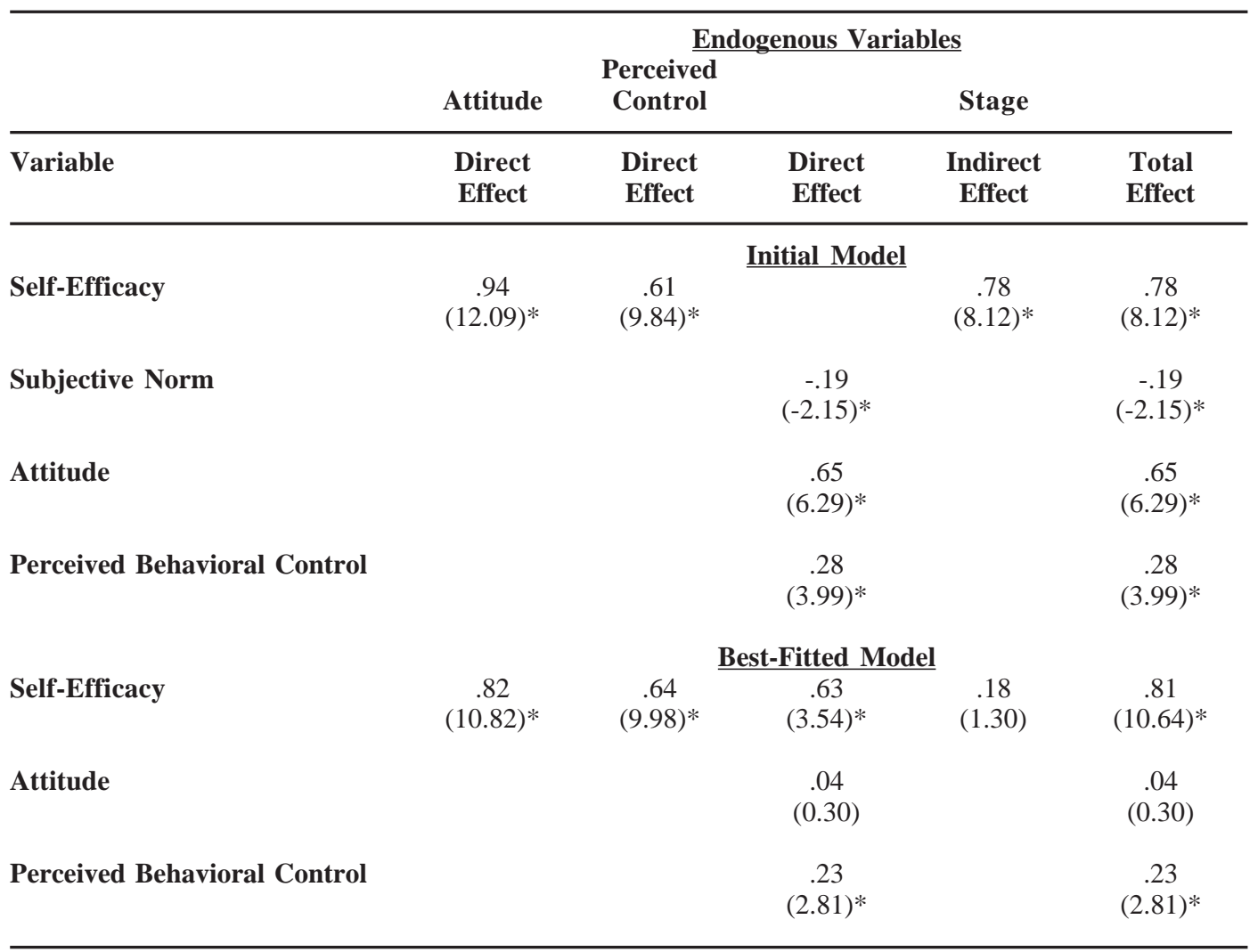

* $\quad$ Critical value for $t \geq 1.96$ and significant $\geq .05$.

"exercising but not regularly" (preparation) and "exercising regularly within the last 6 months" (action), the significant mean differences were behavioral beliefs, attitude, and external constraints, Tukey $H S D(4,463)=-2.06,-.68,-.36, \mathrm{P} \geq .04$, respectively. Between "exercising regularly within the last 6 months" (action) and "exercising regularly longer than 6 months" (maintenance), none of the mean differences were significant differences.

\section{DISCUSSION}

The current study addressed a theoretical debate regarding the contributions of self-efficacy and the theory of planned behavior and incorporating stages of readiness to exercise among a high-risk popu- lation of blue-collar workers. The strongest single explanatory variable of bluecollar workers' stage of readiness for exercise was self-efficacy. This finding supports Bandura's ${ }^{22}$ contention that selfefficacy beliefs account for most of the variance in expected outcomes when performance determines outcome. The most important construct in this study, therefore, was self-efficacy, and the variables of the theory of planned behavior were subjugated to self-efficacy.

Significant relationships also were found between self-efficacy and attitude and perceived behavioral control. This finding also supports comments by Bandura $^{22}$ that attitude, comprising outcome expectancies and evaluations of those outcomes, would depend largely on 


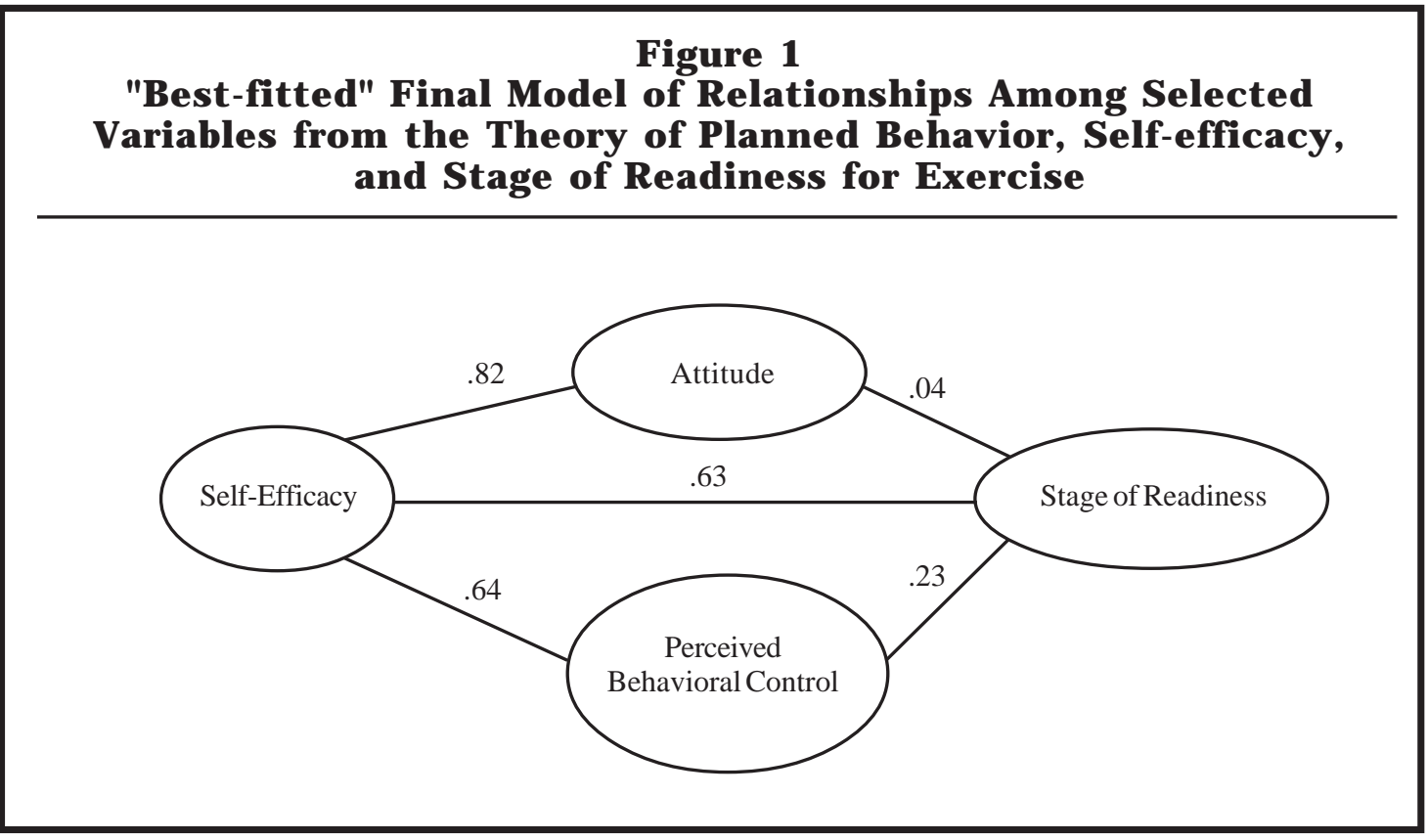

a person's ability or self-efficacy to perform the behavior. Perceived control may arise from the perception of one's capabilities or incapabilities (ie, self-efficacy expectations). The descriptive data in this study suggest that individuals with higher levels of self-efficacy are more confident in their ability to exercise and perceive greater control over optimizing required opportunities and resources to engage in physical activity. The initial LISREL model showed that the variance explained in attitude by self-efficacy was $88 \%$, and self-efficacy explained $37 \%$ of variance in perceived behavioral control. In the final model, the variances explained by self-efficacy change slightly to 67\% (attitude) and 41\% (perceived behavioral control). The influence of attitude on the stages of readiness to exercise drops from a variance of $42 \%$ to $0 \%$, respectively, when a direct path from selfefficacy to stage was added. In addition, self-efficacy, mediated by perceived behavioral control, was found to explain stage of readiness for exercise whereas attitude as a mediator variable had a small, nonsignificant effect on stage of readiness. Consequently, the direct effect of self-efficacy had a much larger effect on stage of readiness for exercise than did either of the 2 mediated effects.
However, it is important not to throw out the baby with the bath water. Examination of the univariate and post hoc tests of variables provides another perspective of the data that might be helpful in planning and conducting interventions. These analyses showed that self-efficacy, along with a composite of variables from the theory of planned behavior, differentiated workers by stage of readiness for exercise. The message emphasis for precontemplators in this population should be on exposure to almost all the variables from the theory of planned behavior and self-efficacy with the exception of 2 variables from the theory of planned behavior: difficulty and control. The message for these workers who are contemplating exercise would be developed from only 2 self-efficacy variables, external and personal constraints. A message to move persons from preparation to action in this study should focus on behavioral beliefs, attitude, and self-efficacy (external constraints). The majority of variables identified by the analyses pertain to the first 3 stages (ie, those who do not exercise at all or who exercise irregularly) or the individuals who would benefit the most from exercising. Interestingly, the data correspond to a public health priority to increase the number 
exercising among those not engaging in regular exercise.

Possible limitations of the study should be considered when interpreting the data and planning future research. The first issue is generalizability of the results because this sample was blue-collar workers from one university. A second consideration that also addresses the first is conducting a longitudinal study in the future that tests the same constructs with other worksite populations over time. A third consideration is confounding of measures. Linear structural equation modeling, however, verifies as part of the confirmatory factor analysis, the distinction of measures of constructs. The data in this study show that control beliefs (eg, time for exercise) were similar to the negative behavioral beliefs (eg, is too timeconsuming), which is inconsistent with the theory of planned behavior. Although the separation of beliefs provided information about their importance to stage of readiness in the univariate analyses, perhaps, if control beliefs are assessed in the future, negative behavioral beliefs that correspond to control issues should not be evaluated because the elicited disadvantages of exercising too closely parallel elicitations of control.

The results of this study complement the growing body of knowledge supporting the use of multitheoretical frameworks to explain or predict physical activity behavior. Results revealed that self-efficacy and the theory of planned behavior helped identify potential determinants of behavior related to stage of readiness to engage in exercise. Given the complexity of physical activity behavior, it is important to continue to integrate theories in order to devise the most parsimonious theoretical model with practical application that accounts for the greatest variance in physical activity behaviors among a particularly high-risk population, bluecollar workers.

\section{Acknowledgments}

This study was supported in part by Grant No. 1 F31 NR07013-01A1 from the National Institute of Nursing Research and Great Lakes Center for Occupational and Environmental Safety and Health, University of Illinois at Chicago.

The authors wish to thank anonymous reviewers for their comments, which improved the paper.

\section{REFERENCES}

1.U.S. Department of Health and Human Services. Physical Activity and Health: A Report of the Surgeon General. Atlanta, GA: U.S. Department of Health and Human Services, Centers for Disease Control and Prevention, National Center for Chronic Disease Prevention and Health Promotion 1996:3-207.

2.Alexy BB. Factors associated with participation or nonparticipation in a workplace wellness center. Res Nurs Health. 1991;14:3340 .

3.Conrad P. Who comes to work-site wellness programs? A preliminary review. J Occup Med. 1987;29:317-320.

4.Lusk SL, Kerr MJ, Ronis DL. Health-promoting lifestyles of blue-collar, skilled trade, and white-collar workers. Nurs Res. 1995;44:2024.

5.Cox MH. Fitness and lifestyle programs for business and industry: problems in recruitment and retention. J Card Rehabil. 1984;4:136142 .

6.King AC, Carl F, Birkel L, et al. Increasing exercise among blue-collar employees: the tailoring of worksite programs to meet specific needs. Prev Med. 1988;17:357-365.

7.Shephard RJ. Exercise adherence in corporate settings: personal traits and program barriers. In Dishman RK, (Ed.). Exercise Adherence: Its Impact on Public Health. Champaign, IL: Human Kinetics Books 1988:305-319.

8.Shephard RJ. Worksite fitness and exercise programs: a review of methodology and health impact. Am J Health Promot. 1996;10:436-452.

9.Campbell MK, Tessaro I, DeVillis B, et al. Tailoring and targeting a worksite health promotion program to address multiple health behaviors among blue-collar women. Am J Health Promot. 2000;14:306-313.

10.Ajzen I. Attitudes, Personality, and Behavior. Chicago, IL: Dorsey Press 1988:112-145.

11.Prochaska J, DiClemente C. Stages and processes of self-change in smoking: toward an integrative model of change. $J$ Consult Clin Psychol. 1983;51:390-395.

12.Blue CL. The predictive capacity of the Theory of Reasoned Action and the Theory of Planned Behavior in exercise research: an integrated literature review. Res Nurs Health. 1995; 18:105-121.

13.Godin G. The theories of reasoned action and planned behavior: overview of findings, emerging research problems and usefulness of exercise promotion. Journal of Applied Sport Psychology. 1993;5:141-157.

14.Hausenblas HA, Carron AV, Mack DE. Application of the theories of reasoned action and planned behavior to exercise behavior: a metaanalysis. Journal of Sport and Exercise Psychology. 1997; 19:36-51.

15.Armitage CJ, Conner M. Efficacy of the theory of planned behaviour: a meta-analytic review. Br J Soc Psychol. 2001;40:471-499.

16. Cole G, Leonard B, Hammond S, et al. Using 
"stages of behavioral change" constructs to measure the short-term effects of a worksitebased intervention to increase moderate physical activity. Psychol Rep. 1998;82:615-618.

17. Marcus $\mathrm{BH}$, Owen N. Motivational readiness, self-efficacy, and decision-making for exercise. J Appl Soc Psychol. 1992;22:3-16.

18. Marcus BH, Selby VC, Niaura RS, et al. Selfefficacy and the stages of exercise behavior change. Res $Q$ Exerc Sport. 1992;63:60-66.

19. Marcus BH, Simkin LR. The stages of exercise change. J Sports Med Phys Fitness. 1993;33:8388.

20.Courneya KS. Understanding readiness for regular physical activity in older individuals: an application of the theory of planned behavior. Health Psychol. 1995;14:80-87.

21. Courneya KS, Nigg CR, Estabrooks PA. Relationships among the theory of planned behavior, stages of change, and exercise behavior in older persons over a 3-year period. Psychol Health. 1998;13:355-367.

22.Bandura A. Self-efficacy: The Exercise of Control. New York: WH Freeman and Company 1997:1-284.

23.McAuley E, Blissmer B. Self-efficacy determinants and consequences of physical activity. Exerc Sport Sci Rev. 2000;28:85-88.

24.Armstrong CA, Sallis JF, Hovell MF, et al. Stages of change, self-efficacy, and the adoption of vigorous exercise: a prospective analysis. Journal of Sport and Exercise Psychology. 1993; 15:390-402.

25.Cardinal BJ. The transtheoretical model of behavior change as applied to physical activity and exercise: a review. Journal of Physical Education and Sport Science. 1995;8:32-45.

26. Marcus BH, Eaton CA, Rossi JS, et al. Selfefficacy, decision-making, and stages of change: an integrative model of physical exercise. J Appl Soc Psychol. 1994;24:489-508.

27.Rogers WM, Courneya KS, Bayduza AL. Examination of the transtheoretical model and exercise in 3 populations. Am J Health Behav. 2001;25:33-41.

28.Terry DJ, O'Leary JE.The theory of planned behaviour: the effects of perceived behavioural control and self-efficacy. $\mathrm{Br} J$ Soc Psycho. 1995;34:199-220.

29.Armitage CJ, Conner M. Distinguishing perceptions of control from self-efficacy: predicting consumption of a low-fat diet using the theory of planned behavior. J Appl Soc Psychol. 1999;29:72-90.

30.Armitage CJ, Conner M. The theory of planned behaviour: assessment of predictive validity and 'perceived control.' Br J Soc Psychol. 1999;38:35-54.

31.Manstead ASR, van Eekelen SAM. Distin- guishing between perceived behavioral control and self-efficacy in the domain of academic achievement intentions and behaviors. J Appl Soc Psychol. 1998;28:1375-1392.

32.Ajzen I. Attitude structure and behavior. In Pratkanis AR, Breckler SJ, Greenwald AG, (Eds.), Attitude Structure and Function. Hillsdale, NJ: Lawrence Erlbaum 1989:251.

33.Ajzen I. From intentions to actions: a theory of planned behavior. In Kuhl J, Beckmann J, (Eds.), Action Control: From Cognition to Behavior. New York, NY: Springer-Verlag 1985:11-39.

34. Cohen J. Statistical Power Analysis for the Behavioral Sciences (2 ${ }^{\text {nd }}$ ed). Hillsdale, NJ Lawrence Erlbaum 1988:407-424.

35.Ajzen I, Fishbein M. Understanding Attitudes and Predicting Social Behavior. Englewood Cliffs, NJ: Prentice-Hall 1980:63-64.

36.Pate R, Pratt M, Blair SN, et al. Physical activity and public health: a recommendation from the Centers for Disease Control and Prevention and the American College of Sports Medicine. JAMA. 1995;273:402-407.

37.Jöreskog KG, Sörbom D. LISREL 8. Chicago: Scientific Software International 1993.

38.Nunnally JC, Bernstein IH. Psychometric Theory $\left(3^{\text {rd }}\right.$ ed). New York: McGraw-Hill 1994:447-490.

39. Osgood CE, Suci GJ, Tannenbaum P. The Measurement of Meaning. Chicago: University of Illinois Press 1957:76-124.

40.Sallis JF, Pinski RB, Grossman RM, et al. The development of self-efficacy scales for healthrelated diet and exercise behaviors. Health Educ Res. 1988;3:283-292.

41. Muto T, Saito T, Sakurai H, et al. The development of a self-efficacy scale for exercise behavior. Keio J Med. 1992;41:21-24.

42.Bollen KA. Structural Equations with Latent Variables. New York: John Wiley \& Sons 1989:179-225.

43.Godin G, Shephard RJ. A simple method to assess exercise behavior in the community. Can J Appl Sport Sci. 1985;10:141-146.

44. Hayduk LA. Structural Equation Modeling with LISREL: Essentials and Advances. Baltimore: The Johns Hopkins University Press 1987:122-123.

45.Godin G, Jobin J, Bouillion J. Assessment of leisure time exercise behavior by self-report: A concurrent validity study. Can J Public Health. 1986;77:359-362.

46. Strahan R, Gerbasi KC. Short, homogeneous versions of the Marlow-Crowne Social Desirability Scale. J Clin Psychol. 1972;28:191-193.

47.SPSS Inc. Statistical Package for the Social Sciences. Chicago: SPSS Inc. 1995. 